\title{
Noncoding RNA in Cholangiocarcinoma
}

\author{
Massimiliano Salati ${ }^{1,2}$ Chiara Braconi, MD, $\mathrm{PhD}^{1,3}$ \\ ${ }^{1}$ Division of Cancer Therapeutics, The Institute of Cancer Research, \\ London, United Kingdom \\ 2 Department of Medical Oncology, University Hospital of Modena \\ and Reggio Emilia, Modena, Italy \\ ${ }^{3}$ Gastrointestinal and Lymphoma Unit, The Royal Marsden NHS Trust \\ Surrey and London, London, United Kingdom
}

\begin{abstract}
Address for correspondence Chiara Braconi, MD, PhD, Division of Cancer Therapeutics, The Institute of Cancer Research, 7N1 Haddow Building, 15 Cotswold Road, Sutton SM2 5NG, London,

United Kingdom (e-mail: Chiara.braconi@icr.ac.uk).
\end{abstract}

Semin Liver Dis 2019;39:13-25.

\begin{abstract}
Keywords

- cholangiocarcinoma

- biliary cancer

- microRNA

- biomarker

Cholangiocarcinomas (CCAs) are tumors with a dismal prognosis. Early diagnosis is a key challenge because of the lack of specific symptoms, and the curability rate is low due to the difficulty in achieving a radical resection and the intrinsic chemoresistance of CCA cells. Noncoding RNAs (ncRNAs) are transcripts that are not translated into proteins but exert their functional role by regulating the transcription and translation of other genes. The discovery of the first ncRNA dates back to 1993 when the microRNA (miRNA) lin-4 was discovered in Caenorhabditis elegans. Only 10 years later, miRNAs were shown to play an oncogenic role in cancer cells and within 20 years miRNA therapeutics were tested in humans. Here, the authors review the latest evidence for a role for ncRNAs in CCA and discuss the promise and challenges associated with the introduction of ncRNAs into clinical practice.
\end{abstract}

Cholangiocarcinoma (CCA) is a rare solid tumor arising from the biliary tree. CCAs are classified as intrahepatic (iCCA), perihilar (pCCA), or distal (dCCA), according to their anatomical location within the biliary tree, ${ }^{1-5}$ and each subtype has unique epidemiological, clinical, and biological features. The incidence of CCA varies greatly across the world, reflecting different environmental and genetic risk factors, and has steadily increased over the last four decades, particularly that of iCCA. ${ }^{6}$ In the Western world, the incidence of CCA varies from 0.3 to 3.5 cases per 100,000, whereas in Thailand, where it peaks, there are 80 cases per $100,000{ }^{7}$ Primary sclerosing cholangitis (PSC) is the most established predisposing factor to CCA in Western countries, while hepatobiliary fluke infestation and hepatolithiasis are well-documented risk factors in Eastern countries. ${ }^{8}$ Late diagnosis and resistance to conventional therapies largely account for an almost invariably dismal prognosis. Surgical resection followed by adjuvant therapy is the only curative approach recommended by international practice guidelines. ${ }^{9}$ However, these are feasible in less than $30 \%$ of cases, and even in these cases, 5 -year overall survival (OS) is disappointing ranging from 20 to $40 \% .{ }^{10}$ Most patients present with unresectable advanced disease at diagnosis and can only be offered palliative treatment, with an associated median OS of less than 12 months. ${ }^{11,12}$ Huge efforts are being made by the research community to discover novel therapeutics for CCA, along with tumor biomarkers that could aid diagnosis, predict treatment efficacy, or improve prognostication. In the past few years, high-throughput technologies have enabled extensive genome, exome, and transcriptome sequencing unveiling, among other things, the regulatory potential of noncoding RNA (ncRNA). ${ }^{13}$ In this article, we review the role of ncRNAs in cholangiocarcinogenesis and tumor progression, as well as the potential for ncRNAs to be incorporated into the clinical management of CCA patients.

\section{The Genomic Landscape of Cholangiocarcinoma}

The clinical heterogeneity of CCA is reflected also at the molecular level. Genome profiling studies have identified numerous genetic aberrations that affect metabolic, mitogenic, chromatin remodeling, and DNA repair signaling pathways. Notably, the mutational spectrum of CCA has been reported to vary according to the anatomical subtype and etiology. Isocitrate dehydrogenase 1 or 2 (IDH1/2) mutations (4.9-36\%), fibroblast growth factor receptor 1-3 (FGFR 1-3) published online

December 7, 2018
Copyright $\odot 2019$ by Thieme Medical Publishers, Inc., 333 Seventh Avenue, New York, NY 10001, USA. Tel: +1(212) 584-4662.
DOI https://doi.org/ 10.1055/s-0038-1676097. ISSN 0272-8087. 
fusions, mutations and amplifications (11-45\%), and BAP-1 mutations (13\%) occur more frequently in iCCA; on the contrary, KRAS mutations (8.3-42\%), SMAD4 mutations (21\%), and ERBB2/3 amplifications (11-17\%) are observed more commonly in extrahepatic CCA. ${ }^{14}$ Regarding etiology, liver fluke-driven CCA are enriched in ERBB2 amplifications and TP53 mutations; by contrast, non-liver fluke-associated CCA present high copy-number alterations and PD-1 (programmed death 1)/PD-L2 (programmed death-ligand 2) expression, or epigenetic mutations (IDH1/2, BAP-1) and FGFR/PRKA-related gene rearrangement. ${ }^{15,16}$

Given the considerable genetic diversity of CCA with low penetrance driver aberrations and dependence on multiple pathways, several attempts have made to molecularly subtyping CCA to get clinical useful information. In a collaborative effort by the International Cancer Genome Consortium an integrated genomic, epigenomic, and transcriptomic analysis was performed on 489 CCAs from 10 countries leading to the identification of 4 subgroups, each harboring distinct genetic, epigenetic, and clinicopathologic features. ${ }^{16}$

Notably, this molecular clustering, thought to reflect the multifactorial interplay between genetics, epigenetics, and environment in cholangiocarcinogenesis, displays a prognostic value (cluster 3 and 4 have a better prognosis than cluster 1 and 2) and provides an in-depth characterization of CCA beyond anatomical site (e.g., iCCA are splitted across all 4 cluster and the subtyping can be reproduced within each anatomical location separately).

Moreover, through multiplatform analyses (somatic mutations, DNA methylation, copy number, RNA expression) in a set of predominantly iCCA, The Cancer Genome Atlas group identified a molecularly distinct subtype of IDH-mutant CCA, displaying increased mitochondrial gene expression and DNA copy number and low chromatin modifier gene expression. ${ }^{17}$ Interestingly, in the same study, the authors found 21 long ncRNAs (lncRNAs) that correlated with the chromatin modifier signature, whereas one miRNA (miR194-5p) was upregulated in the IDH-mutant subtype and negatively associated with the chromatin modifier signature.

\section{Noncoding RNAs}

Although at least $80 \%$ of the human genome is biologically active, only roughly $3 \%$ is transcribed into protein-coding mRNAs. ${ }^{18}$ The near totality of it, once termed "junk," is now known to be made up of RNA that is transcribed but not translated into proteins, the so-called ncRNA. This term encompasses several classes of transcripts that can be classified according to their length into small (18 to 200 nucleotides) and long ( $>200$ nucleotides) RNAs, and according to their function into housekeeping (e.g., ribosomal RNA and transfer RNA) and regulatory (e.g., microRNA, piwi-interacting RNA, lncRNA) RNAs. ${ }^{19}$ ncRNAs are master regulators of transcription, transcript stability, and translation of protein-coding transcripts, with roles in both physiological processes and human diseases, including cancer. Among ncRNAs, microRNAs (miRNAs), transcripts of 18 to 24 nucleotides in length, are the most extensively studied. As a result of conserved seed pairing over just 7 or 8 bases on multiple mRNAs, a single miRNA has the potential to target thousands of genes. ${ }^{20}$ miRNAs have been traditionally regarded as negative regulators of gene expression that, upon binding to the 3 ' untranslated region of a target mRNA, leads to its translational inhibition or degradation, thus downregulating the final protein output of protein-coding genes. However, over recent years, new insights into miRNA properties have emerged that are unveiling much broader regulatory functions than initially thought. Indeed, they were shown to target various noncanonical sites such as DNA promoter regions, RNA 5' untranslated region, other ncRNAs, and proteins. Moreover, miRNAs can upregulate protein translational both directly, via recruitment of protein complexes, and indirectly, unleashing the translation repression exerted by inhibitory proteins. Again, there is also evidence that miRNAs can affect the Toll-like receptor signaling and downstream pathways (e.g., nuclear factor-kB pathway) through an agonist effect on Toll-like receptors. ${ }^{21}$

With regard to their link with cancer, miRNAs have been shown to be deregulated in almost all human tumor types and to affect several steps of carcinogenesis by acting either as oncogenes or tumor suppressors. ${ }^{22,23}$ More interestingly, signatures consisting of aberrantly expressed miRNAs have been found to have specific diagnostic and prognostic value. ${ }^{13}$ On this basis, miRNAs have been regarded as promising tools for improving the management of cancer patients. Next, we discuss the involvement of ncRNAs in the regulation of cancer hallmarks, and the challenges associated with translating these findings into the clinic (-Fig. 1).

\section{Role of miRNAs in Cholangiocarcinogenesis}

miRNA dysregulation has been shown to affect almost all CCA hallmarks, ranging from sustained cell proliferation to cancer-related inflammation (-Tables $\mathbf{1}$ and $\mathbf{2}$ ).

\section{Sustaining Proliferative Signaling}

The earliest evidence for the role of ncRNAs in cholangiocarcinogenesis came from a study by Meng et $\mathrm{al}^{24}$ in which they found CCA cells had deregulated miRNA expression and that miR-21 had a predominant role in enhancing tumor cell growth. miR-21 overexpression was confirmed in independent cohorts of human primary CCA patients and its oncogenic role was linked, at least partially, to the inhibition of programmed cell death 4 and TIMP metallopeptidase inhibitor 3 expression. ${ }^{25}$ miR-26a has also been shown to be upregulated in human CCA, leading to increased proliferation of CCA cells via activation of $\beta$-catenin-dependent genes. ${ }^{26}$ It is interesting to note that miR-26 was found to be an oncosuppressor in hepatocellular carcinoma (HCC), the other form of primary liver cancer, ${ }^{27}$ underlining the peculiarities of tissue-dependent miRNA expression. More recent evidence supports an oncogenic role for miR-191 and miR-181c in CCA, specifically their ability to sustain tumor growth and drive cancer aggressiveness. ${ }^{28,29}$ It is likely that several miRNAs with oncogeneic and oncosuppressive properties interplay within cancer cells to promote a given phenotype. For instance, Olaru and colleagues identified a role for miR-494 as a negative regulator of 


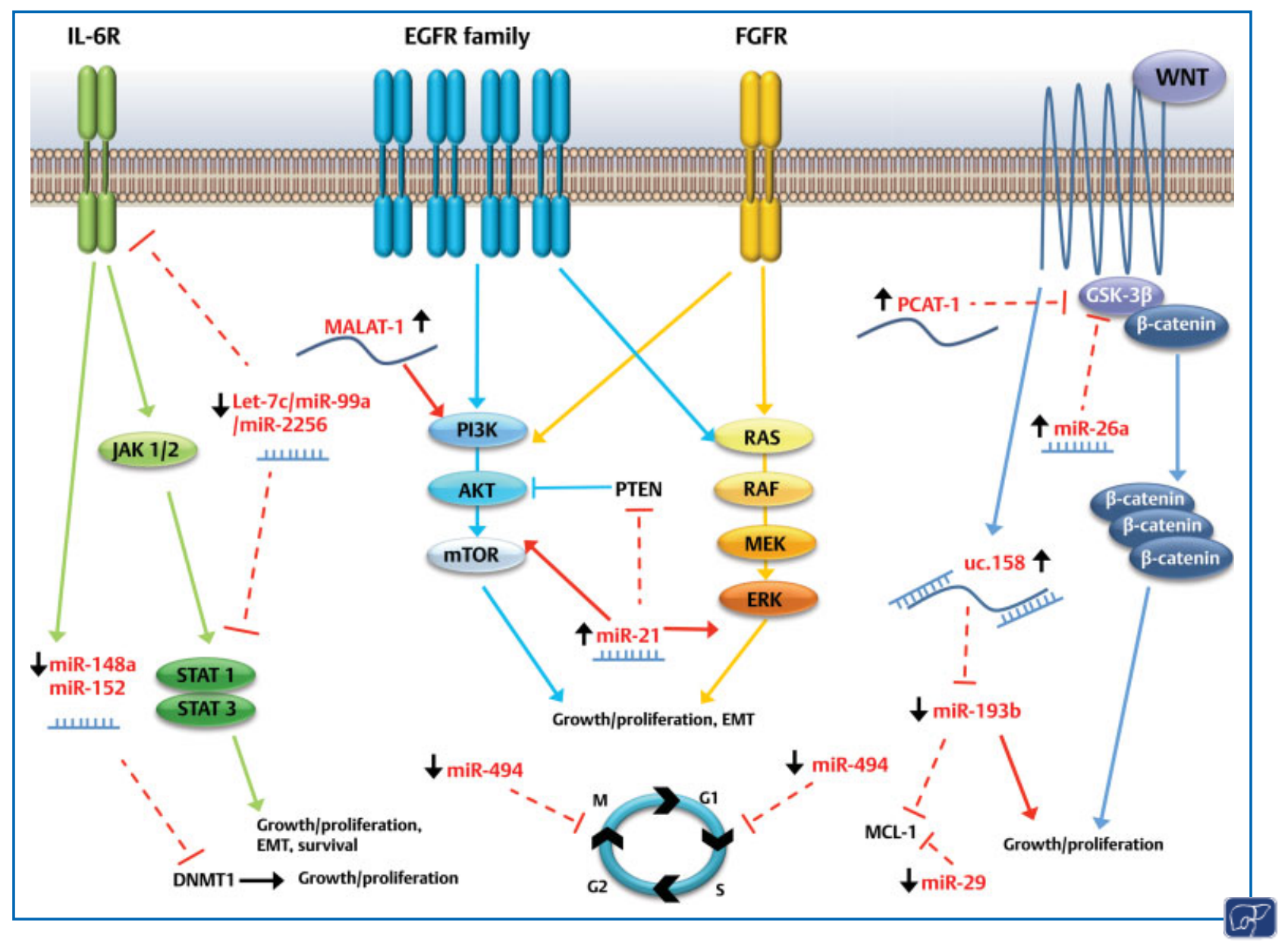

Fig. 1 Selected noncoding RNAs (ncRNAs) interacting with their relative targets within major oncogenic signaling pathways altered in cholangiocarcinoma. Upward black arrow shows upregulated ncRNAs, while downward black arrow refers to downregulated ncRNAs. Continuous arrows show an activating function, while dashed line refers to inhibitory function.

cancer cell growth by showing that miR-494 expression is downregulated in CCA samples and that it has the ability to inhibit progression through the cell cycle. ${ }^{30}$ Moreover, miRNAs often affect a cancer cell phenotype as a result of their ability to modulate multiple key players. For example, the expression of miR-494 induces a global deregulation of genes involved in progression through the cell cycle including cyclin-dependent kinase 6, cyclin-dependent kinase 4, cyclin D1, cyclin E2, histone deacetylase $1, R B$ transcriptional corepressor 1, polo-like kinase 1, pituitary tumor-transforming 1, cyclin B1, cyclin-dependent kinase 2, and DNA topoisomerase II ${ }^{31}$

\section{Resisting Cell Death}

Protection from cell death is another process in which miRNAs are involved. Apoptotic signaling pathways seem to be regulated by a combination of miRNAs with oncosuppressive or oncogenic functions. These include the oncosuppressive miR-29, whose loss in CCA is associated with an increase in the abundance of the antiapoptotic protein myeloid cell leukemia sequence $1,{ }^{31}$ and the oncogenic miR-25, whose high expression in CCA cells is responsible for resistance to tumor necrosis factor (TNF)-related apoptosis-inducing ligand (TRAIL)-induced apoptosis. ${ }^{32}$

\section{Activating Invasion and Metastasis}

It was recently reported that changes in miRNA expression induce the epithelial-mesenchymal transition (EMT), a process whereby epithelial cells lose polarity and cell-to-cell adhesion to acquire invasiveness and migratory capabilities like mesenchymal elements. A study by Oishi et al, which employed integrative pathway analysis, linked miR-200c signaling to the EMT in a subtype of iCCA with stem-like gene expression features, providing an explanation as to why this subtype is clinically aggressive. ${ }^{33}$ Overexpression of miR-21 was also associated with typical EMT features such as a low level of E-cadherin and high levels of $\mathrm{N}$-cadherin and vimentin, suggesting how a single miRNA can sustain tumor progression by acting on different pathways. ${ }^{34,35}$ In addition, it has been shown that miRNAs involved in the regulation of EMT can increase the metastatic behavior of human CCA cells. $^{36-38}$

\section{Tumor-promoting Inflammation}

Chronic biliary tract inflammation is thought to be the most robust factor to drive cholangiocarcinogenesis. CCA often arises in the setting of conditions such as PSC, hepatolithiasis, choledochal cysts, and liver fluke infestations. Moreover, the 
Table 1 Selected oncogenic miRNAs involved in cholangiocarcinoma initiation and progression

\begin{tabular}{|c|c|c|c|c|c|c|}
\hline miRNA & Expression $^{a}$ & Tumor type & Target genes & Function & Source & Ref. \\
\hline miR-21 & Up & $\begin{array}{l}\text { CCA, iCCA, } \\
\text { Op-CCA }\end{array}$ & $\begin{array}{l}\text { PI3K, PDCD4, TIMP3, } \\
\text { RECK, TPM1, 15PGDH, } \\
\text { PTPN14, PTEN, KLF4, } \\
\text { AKT, ERK }\end{array}$ & $\begin{array}{l}\text { Tumor growth, } \\
\text { invasion, } \\
\text { migration } \\
\text { EMT, }\end{array}$ & $\begin{array}{l}\text { Human cell lines, } \\
\text { human tissue, } \\
\text { mouse tissue }\end{array}$ & $24,25,29,34,35,46$ \\
\hline miR-25 & Up & CCA & $D R 4$ & Antiapoptotic & $\begin{array}{l}\text { Human cell lines, } \\
\text { human tissue, }\end{array}$ & 32 \\
\hline miR-26a & Up & CCA & GSK-3 $\beta$ & Tumor growth & $\begin{array}{l}\text { Human cell lines, } \\
\text { human tissue, } \\
\text { mouse tissue }\end{array}$ & 26 \\
\hline miR-31 & Up & iCCA & RASA1 & $\begin{array}{l}\text { Proliferation, } \\
\text { antiapoptotic }\end{array}$ & $\begin{array}{l}\text { Human cell lines, } \\
\text { human tissue, }\end{array}$ & 27 \\
\hline miR-141 & Up & CCA & CLOCK & Proliferation & $\begin{array}{l}\text { Human cell lines, } \\
\text { human tissue, } \\
\text { mouse tissue }\end{array}$ & 24 \\
\hline miR-210 & Up & CCA & MNT & Proliferation & Mouse tissue & 105 \\
\hline miR-221 & Up & eCCA & PTEN & $\begin{array}{l}\text { Invasion, } \\
\text { migration, EMT }\end{array}$ & $\begin{array}{l}\text { Human cell lines, } \\
\text { human tissue, }\end{array}$ & 37 \\
\hline $\mathrm{miR}-421$ & Up & CCA & $F X R$ & $\begin{array}{l}\text { Proliferation, } \\
\text { migration }\end{array}$ & $\begin{array}{l}\text { Human cell lines, } \\
\text { human tissue }\end{array}$ & 106 \\
\hline Let-7a & Up & CCA & NF2 & Survival & $\begin{array}{l}\text { Human cell lines, } \\
\text { mouse tissue }\end{array}$ & 42 \\
\hline miR-24 & Up & iCCA, eCCA & MEN1 & $\begin{array}{l}\text { Proliferation, } \\
\text { migration, } \\
\text { angiogenesis }\end{array}$ & $\begin{array}{l}\text { Human cell lines, } \\
\text { human tissue, } \\
\text { mouse tissue }\end{array}$ & 107 \\
\hline
\end{tabular}

Abbreviations: 15PGDH, 15-hydroxyprostaglandin dehydrogenase; Akt, AKT serine/threonine kinase; CCA, cholangiocarcinoma; CLOCK, circadian locomotor output cycles kaput protein; eCCA, extrahepatic cholangiocarcinoma; EMT, epithelial mesenchymal transition; ERK, extracellular signal-regulated kinase; FXR, farnesoid X receptor; GSK-3ß, glycogen synthase kinase 3 beta; HCV-iCCA, HCV-related intrahepatic cholangiocarcinoma; iCCA, intrahepatic cholangiocarcinoma; KLF4, Kruppel-like factor 4; MEN, Menin 1.Mnt, MAX Network Transcriptional Repressor; NF2, neurofibromin 2; Op-CCA, opisthorchiasis-associated cholangiocarcinoma; pCCA, perihilar cholangiocarcinoma; PDCD4, programmed cell death 4; PI3K, phosphoinositide-3-kinase; PTEN, phosphatase and tensin homolog; PTPN14, protein tyrosine phosphatase, non-receptor type 14; RASA1, RAS P21 Protein Activator 1; RECK, reversion-inducing cysteine-rich protein with Kazal motifs; Ref., references; TIMP3, TIMP metallopeptidase inhibitor 3; TPM1, tropomyosin 1.

${ }^{a}$ Compared with normal biliary cells/tissue.

inflammation-associated cytokine interleukin-6 (IL-6) is increased in both the biliary tract and the systemic circulation of CCA patients, where it promotes neoplastic growth and survival through autocrine and/or paracrine mitogenic signals. $^{39,40}$

Persistent IL-6 stimulation can alter miRNA expression both in vitro and in vivo and the resulting upregulation of let7 contributes to IL-6-dependent signal transducer and activator of transcription 3 (STAT-3) survival signaling in malignant human cholangiocytes. ${ }^{41,42}$ In addition, IL-6 can favor CCA growth by methylation-dependent regulation of miR370 and associated targets such as the transcript of the oncogene mitogen-activated protein kinase kinase kinase 8 (MAP3K8) ${ }^{43}$ Enforced IL-6 expression can negatively modulate miR-148a and miR-152 in human CCA cells, leading to an increase in the level of DNA methyltransferase 1 and silencing of critical tumor suppressor genes such as Ras association domain family member 1 (RASSF1) and cyclindependent kinase inhibitor $2 \alpha$ (CDKN2A, also known as p16INK4a) ${ }^{44}$ Distinct miRNA signatures were also identified in Opisthorchis viverrini-driven CCA, suggestive of the effect of inflammation on miRNAs. ${ }^{45,46}$ This evidence strengthens the biological basis for the interplay between an inflammatory microenvironment, epigenetics, and molecular events involved in cholangiocarcinogenesis, along with providing a rationale for targeting miRNAs that control the inflammatory response.

\section{Microenvironment}

The tumor microenvironment is a complex network made up of both cancer cells and reactive peritumoral stroma, the latter being enriched for various host cells including cancerassociated fibroblasts (CAF), endothelial cells, immune cells, and tumor-associated macrophages. ${ }^{47,48}$ Tumor-reactive stroma has been hypothesized to be a pivotal driver of CCA initiation and progression by affecting the behavior of cancer cells. The loss of miR-15 was found to be specific for CCAassociated fibroblasts when compared with skin-derived fibroblasts, suggesting a key role for ncRNAs in driving the transformation of stromal cells into CAFs that have a functional role in promoting cancer growth and chemoresistance. ${ }^{49}$ miRNAs have lately emerged as novel players in the intercellular communication network that exists between different cell types in the tumor microenvironment. 
Table 2 Selected oncosuppressor miRNAs in cholangiocarcinoma initiation and progression

\begin{tabular}{|c|c|c|c|c|c|c|}
\hline miRNA & Expression $^{a}$ & $\begin{array}{l}\text { Tumor } \\
\text { type }\end{array}$ & Target genes & Function & Source & Ref. \\
\hline miR-34a & Down & $\begin{array}{l}\text { eCCA, } \\
\text { CCA }\end{array}$ & Per-1, SMAD4 & $\begin{array}{l}\text { Proliferation, invasion, } \\
\text { migration, EMT }\end{array}$ & $\begin{array}{l}\text { Human cell lines, } \\
\text { human tissue }\end{array}$ & 103,108 \\
\hline miR-29b & Down & CCA & Mcl1 & Antiapoptotic & Human cell lines & 31 \\
\hline miR-26a & Down & CCA & KRT19 & $\begin{array}{l}\text { Suppression of } \\
\text { tumor growth }\end{array}$ & $\begin{array}{l}\text { Human cell lines, } \\
\text { human tissue, } \\
\text { mouse tissue }\end{array}$ & 83 \\
\hline miR-101 & Down & CCA & VEGF, COX-2 & Angiogenesis & $\begin{array}{l}\text { Human cell lines, } \\
\text { human tissue }\end{array}$ & 109 \\
\hline miR-124 & Down & HCV-iCCA & SMYD3 & Invasion, migration & Human cell lines, & 110 \\
\hline miR-138 & Down & CCA & RhoC & $\begin{array}{l}\text { Proliferation, } \\
\text { invasion, migration }\end{array}$ & Human cell lines & 38 \\
\hline miR-144 & Down & CCA & LIS1 & $\begin{array}{l}\text { Proliferation, } \\
\text { invasion, migration }\end{array}$ & $\begin{array}{l}\text { Human cell lines, } \\
\text { human tissue, } \\
\text { mouse tissue }\end{array}$ & 111 \\
\hline $\begin{array}{l}\text { miR-148a } \\
\text { miR-152 }\end{array}$ & Down & CCA & DNMT-1 & Proliferation & $\begin{array}{l}\text { Human cell lines, } \\
\text { mouse tissue }\end{array}$ & 44 \\
\hline $\mathrm{miR}-200 \mathrm{~b} / \mathrm{c}$ & Down & $\begin{array}{l}\text { CCA, } \\
\text { iCCA }\end{array}$ & $\begin{array}{l}\text { SUZ12, ROCK2, } \\
\text { NCAM1 }\end{array}$ & $\begin{array}{l}\text { Invasion, migration, } \\
\text { EMT, drug resistance }\end{array}$ & $\begin{array}{l}\text { Human cell lines, } \\
\text { human tissue, } \\
\text { mouse tissue }\end{array}$ & 112 \\
\hline miR-204 & Down & $\overline{i C C A}$ & Slug, $B C l-2$ & $\begin{array}{l}\text { Invasion, migration, } \\
\text { EMT, antiapoptotic }\end{array}$ & $\begin{array}{l}\text { Human cell lines, } \\
\text { human tissue }\end{array}$ & 91 \\
\hline miR-214 & Down & iCCA & Twist & EMT & $\begin{array}{l}\text { Human cell lines, } \\
\text { human tissue }\end{array}$ & 36 \\
\hline miR-320 & Down & CCA & Mcl-1 & Antiapoptotic & $\begin{array}{l}\text { Human cell lines, } \\
\text { human tissue }\end{array}$ & 91 \\
\hline $\mathrm{miR}-370$ & Down & CCA & МАРЗК8, WNT10B & Proliferation & $\begin{array}{l}\text { Human cell lines, } \\
\text { human tissue, } \\
\text { mouse tissue }\end{array}$ & 43,113 \\
\hline miR-373 & Down & pCCA & MBD2 & Proliferation & $\begin{array}{l}\text { Human cell lines, } \\
\text { human tissue }\end{array}$ & 114 \\
\hline miR-376c & Down & iCCA & GRB2 & $\begin{array}{l}\text { Proliferation, } \\
\text { migration }\end{array}$ & Human cell lines & 115 \\
\hline miR-410 & Down & CCA & XIAP & Proliferation & $\begin{array}{l}\text { Human cell lines, } \\
\text { human tissue, } \\
\text { mouse tissue }\end{array}$ & 43 \\
\hline miR494 & Down & CCA & $\begin{array}{l}\text { CDK6, PLK1, PTTG1, } \\
\text { CCNB1, CDC2, } \\
\text { CDC20 TOP2A, }\end{array}$ & Proliferation & $\begin{array}{l}\text { Human cell lines, } \\
\text { mouse tissue }\end{array}$ & 30,116 \\
\hline $\begin{array}{l}\text { let-7c/ } \\
\text { miR-99a/ } \\
\text { miR-125b }\end{array}$ & Down & CCA & IL-6, IL-6R, IGF1R & $\begin{array}{l}\text { Inflammation, } \\
\text { invasion, migration }\end{array}$ & $\begin{array}{l}\text { Human cell lines, } \\
\text { human tissue, } \\
\text { mouse tissue }\end{array}$ & 41 \\
\hline
\end{tabular}

Abbreviations: Bcl-2, B cell CLL/Lymphoma 2; CCA, cholangiocarcinoma; CCNB1, Cyclin B1; CDC2, Cell Division Control Protein 2 Homolog; CDC20, Cell Division Cycle 20; CDK6, Cyclin Dependent Kinase 6; COX-2, Cyclooxygenase-2; DNMT-1, DNA Methyltransferase 1; eCCA, extrahepatic cholangiocarcinoma; EMT, epithelial mesenchymal transition; GRB2, Growth Factor Receptor Bound Protein 2; HVC-iCCA, HCV-related intrahepatic cholangiocarcinoma; iCCA, intrahepatic cholangiocarcinoma; IGF1R, Insulin Like Growth Factor 1 Receptor; IL-6, Interleukin 6; IL-6R, Interleukin 6 receptor; KRT19, Keratin 19; LIS1, Lissencephaly-1 homolog; MAP3K8, Mitogen-Activated Protein Kinase Kinase Kinase 8; MBD2, Methyl-CpG Binding Domain Protein 2; Mcl1, Myeloid Cell Leukemia Sequence 1; Mcl-1, Myeloid Cell Leukemia Sequence 1; NCAM1, Neural Cell Adhesion Molecule 1; pCCA, perihilar cholangiocarcinoma; Per-1, Period Circadian Regulator 1; PLK1, Polo Like Kinase; PTTG1, Pituitary Tumor-Transforming 1; Ref., references; RhoC, Ras Homolog Family Member C; ROCK2, Rho Associated Coiled-Coil Containing Protein Kinase 2; Slug/Snail Family Transcriptional Repressor 2; SMAD4, SMAD Family Member 4; SMYD3, SET And MYND Domain Containing 3; SUZ12, SUZ12 Polycomb Repressive Complex 2 Subunit; TOP2A, DNA Topoisomerase II Alpha; Twist, Twist Family BHLH Transcription Factor 1; VEGF, Vascular Endothelial Growth Factor; WNT10B, Wnt Family Member 10B; XIAP, X-Linked Inhibitor Of Apoptosis.

${ }^{a}$ Compared with normal biliary cells/tissue. 
miRNAs are released from donor cells in extracellular vesicles (EVs) and can induce phenotypic and functional changes in recipient target cells. Evidence suggests that the ncRNA within EVs released from nonmalignant and malignant cells is different, and that tumor-specific EVs contain short or IncRNAs that can modulate how cells respond to hypoxia, control their growth, and respond to drugs ${ }^{50,51}$. Exosomes, a subtype of EV, can be found in the bile of rat models and influence intracellular signaling mechanisms and cholangiocyte proliferation via interaction with cholangiocyte cilia. ${ }^{52}$ Furthermore, miRNA-loaded vesicles derived from myofibroblasts can selectively target CCA cells, influencing their neoplastic properties both in vitro and in vivo. ${ }^{53}$ Conversely, tumor cells can release EVs that induce mesenchymal stem cells to change the local microenvironmental to enhance CCA cell growth. ${ }^{54}$ A better understanding of such EV-mediated bidirectional interactions, and identification of the ncRNA species that are trafficked between tumor and stromal cells, could offer new CCA prevention strategies and/or therapeutic intervention in CCA patients. More importantly, the discovery that stroma-derived EVs are uniquely suited to deliver materials to CCA cells raises hope that EVs could be exploited to deliver antineoplastic therapies. For example, intravenous injection of miR-195-loaded fibroblast-derived EVs was shown to reach the tumor, decrease tumor size, and improve survival in a rat model of CCA. ${ }^{55}$

\section{Role of Long ncRNAs in Cholangiocarcinoma Biology}

Long ncRNAs are a subgroup of ncRNA transcripts that are longer than 200 nucleotides and not translated into proteins. Functions and mechanisms of action of lncRNAs are different from those of miRNAs and need further characterization. LncRNAs can regulate a myriad of biological processes through interaction with various cellular macromolecules such as DNA, RNA, and proteins, acting either in the nucleus or in the cytoplasm. LncRNAs are involved in the fine regulation of gene expression acting as epigenetic modifiers through recruitment of chromatin remodeling complexes to specific genomic loci, as enhancers in cis of neighboring genes, and as scaffolds for the assembly of transcriptional regulatory molecules. LncRNA can affect several aspects of the post-transcriptional regulation process, including mRNA stability, splicing, and translation. In addition, recent evidence suggests a role for lncRNAs and pseudogenes as sponges for small ncRNAs, behaving as cytoplasmic "controllers" of cell fate.

Several studies have demonstrated that several lncRNAs play fundamental roles in a variety of pathological processes, including cancer. ${ }^{56}$ LncRNA expression was found to be deregulated in human iCCA, with 2,773 upregulated and 2,392 downregulated IncRNAs when compared with paired noncancerous tissue across a cohort of 77 human CCA patients. ${ }^{29}$ Interestingly, these $\ln$ cRNAs seem to regulate genes associated with cancer, hepatic system disease, and signal transduction, supporting a role for lncRNAs in the development and progression of CCA. H19, the first lncRNA discovered, was found overexpressed in both CCA tissues and CCA cell lines, where it contributes to different steps in cholangiocarcinogenesis by promoting cell proliferation, migration, invasion, evasion of apoptosis, and EMT. ${ }^{57}$ Similar oncogenic properties were reported for other lncRNAs such as AFAP1 antisense RNA 1 (AFAP1-AS1), ${ }^{58}$ CPS1 intronic transcript 1 (CPS1-IT1), ${ }^{59}$ metastasis-associated lung adenocarcinoma transcript 1 (MALAT1), promoter of CDKN1A antisense DNA damage-activated RNA (PANDAR), prostate cancer-associated transcript 1 (PCAT1), colon cancer-associated transcript 1 (CCAT1), taurine upregulated 1 (TUG1), urothelial cancer associated 1 (UCA1), and SOX2 overlapping transcript (SOX2-OT) ${ }^{60-64}$ LncRNAs are also involved in sustaining CCA progression induced by inflammation. For example, H19 and HULC are induced by oxidative stress and can deregulate the cellular host inflammatory response by acting on genes such as IL- 6 and $C-X-C$ motif chemokine receptor 4 (CXCR4). ${ }^{65}$ Ultraconserved regions (UCRs) are noncoding genomic segments with more than 200 nucleotides in length that are remarkably conserved between species, with $100 \%$ sequence similarity across the human, mouse, and rat genomes. The deregulation of UCR transcription has been increasingly implicated in human cancers. It has been postulated that the conservation of UCR gene sequences between species indicates that UCRs have an essential functional role, suggesting that an alteration in their transcription may represent the first step in malignant transformation. Transcripts derived from UCRs may be of various lengths, and their 3D structure is likely to impact on their function by affecting their interaction with ribonucleoproteins or their ability to capture small ncRNAs in "spongelike" structures. ${ }^{66,67}$ We and others showed that the deregulation of transcribed-UCR(T-UCR) occurs in the cancer tissues but is already present in the adjacent background tissue, suggesting that it may create a favorable environment for the progression of cancer. ${ }^{66,68}$ Furthermore, we have shown that uc.158 can act downstream of the Wnt pathway and is likely to represent the cellular mediator that promotes CCA cell growth in response to stroma-derived Wnt signaling. More recently, IncRNAs can differentiate between T cell classes more precisely than mRNAs, suggesting lncRNAs are potential drivers of immune cell fate and regulators of the interplay between cancer cells and those in the microenvironment. ${ }^{69}$

\section{Clinical Implications of ncRNAs in Cholangiocarcinoma}

In addition to acting within cells, miRNAs are released and circulate in serum, plasma, and other bodily fluids, either as free RNAs bound to the argonaut RNA-induced silencing complex (RISC) catalytic component or in extracellular vesicles, such as exosomes or microvesicles. ${ }^{70}$ This protects miRNAs from degradation via RNAses and gives them stability and resistance during the storage and handling of patient samples. All of these properties, together with the ability to isolate, characterize, and identify disease-specific miRNA content in tissues and bodily fluids, has raised interest in miRNAs as a gold mine of biomarkers with potential in cancer diagnosis, prognosis, treatment response, and therapy $^{71}$ (- Table 3 ). 
Table 3 miRNAs with clinically promising biomarker potential in cholangiocarcinoma

\begin{tabular}{|c|c|c|c|c|c|c|}
\hline miRNA & Expression $^{\mathrm{a}}$ & $\begin{array}{l}\text { Biological } \\
\text { Source }\end{array}$ & Clinical setting & Role & Impact & Ref. \\
\hline miR-21 & Up & Tissue & Resected CCA & Diagnostic & $\begin{array}{l}95 \% \text { SV, } \\
100 \% \text { SP }\end{array}$ & 82 \\
\hline $\begin{array}{l}\text { miR191, miR486-3p, } \\
\text { miR1274b, miR16, } \\
\text { miR484c }^{c}\end{array}$ & Up & Bile & $\begin{array}{l}\text { Early and advance } \\
\text { stage CCA }\end{array}$ & Diagnostic & $\begin{array}{l}67 \% \text { SV, } \\
96 \% \text { SP }\end{array}$ & 75 \\
\hline $\begin{array}{l}\text { miR-1281, miR-126, } \\
\text { miR-26a, miR-30b, } \\
\text { miR-122 }\end{array}$ & $U p^{b}$ & Serum & PSC vs CCA & $\begin{array}{l}\text { Differential } \\
\text { diagnostic }\end{array}$ & $32-68 \%$ SV, $88-93 \%$ SP & 74 \\
\hline $\begin{array}{l}\text { miR-412, miR-640, } \\
\text { miR-1537, miR-3189 }\end{array}$ & $U^{* *}$ & Bile & PSC vs CCA & $\begin{array}{l}\text { Differential } \\
\text { diagnostic }\end{array}$ & $\begin{array}{l}50-67 \% \text { SV, } \\
89-92 \% \text { SP }\end{array}$ & 74 \\
\hline miR-192, miR-21 & Up & Urine & $\begin{array}{l}\text { Op-CCA vs } \\
\text { healthy people }\end{array}$ & $\begin{array}{l}\text { Differential } \\
\text { diagnostic }\end{array}$ & $81.8 \%$ SV, ${ }^{d} 71.4 \% S^{d}$ & 76 \\
\hline miR-21 & Up & Serum & Resected CCA & Prognostic & PFS, OS & 82 \\
\hline miR-106a & Down & Serum & Resected CCA & Prognostic & OS & 117 \\
\hline miR-203 & Down & Tissue & Resected CCA & Prognostic & OS & 84 \\
\hline miR-26a & Up & Serum & Resected CCA & Prognostic & PFS, OS & 83 \\
\hline $\begin{array}{l}\text { miR-151-3p, } \\
\text { miR-126 }\end{array}$ & $\begin{array}{l}\text { Up } \\
\text { Down }\end{array}$ & Tissue & Resected CCA & Prognostic & OS & 118 \\
\hline miR-21, miR200b & Up & $\begin{array}{l}\text { Human cell } \\
\text { lines, }\end{array}$ & $\begin{array}{l}\text { Response to } \\
\text { gemcitabine }\end{array}$ & Predictive & NA & 24 \\
\hline $\begin{array}{l}\text { miR-29b, miR-205, } \\
\text { miR-221 }\end{array}$ & Down & $\begin{array}{l}\text { Human cell } \\
\text { lines, }\end{array}$ & $\begin{array}{l}\text { Response to } \\
\text { gemcitabine }\end{array}$ & Predictive & NA & 90 \\
\hline miR130a-3p & Up & $\begin{array}{l}\text { Human cell } \\
\text { lines }\end{array}$ & $\begin{array}{l}\text { Response to } \\
\text { gemcitabine }\end{array}$ & Predictive & NA & 119 \\
\hline $\begin{array}{l}\text { miR-320, } \\
\text { miR-204 }\end{array}$ & Down & $\begin{array}{l}\text { Human cell } \\
\text { lines, }\end{array}$ & $\begin{array}{l}\text { Response to } \\
\text { 5-FU }\end{array}$ & Predictive & NA & 91 \\
\hline
\end{tabular}

Abbreviations: 5-FU, 5-fluorouracil; CCA, cholangiocarcinoma; NA, not applicable. Op-CCA, opisthorchiasis-associated cholangiocarcinoma; OS, overall survival; PFS, progression-free survival; PSC, primary sclerosing cholangitis; SP, specificity; SV, sensitivity.

${ }^{a}$ Compared with normal matched counterpart.

bPSC compared with CCA.

'A miRNA-based panel including all five miRs.

${ }^{\mathrm{d} C}$ Combined value of miR-192 and miR-21.

\section{Diagnostic Role}

Cholangiocarcinoma diagnosis is often challenging due to the lack of specific symptoms, the technical difficulty to access tissue, and the intense stroma reaction and paucicellular neoplastic nature of this disease. Thus, there is an urgent need for diagnostic tools that can enable early cancer detection. The pattern of miRNA expression in CCA cell lines and human tissues significantly differs from that in nonmalignant counterparts, suggesting that CCA-specific miRNA expression profiles could be used to develop diagnostic assays. Differentiating between CCA and benign disorders harboring biliary strictures (e.g., PSC) poses a particular challenge since they appear the same when imaged and because of the difficulties associated with obtaining cytological and/or histological samples of sufficient yield. ${ }^{72}$ A combination of two circulating miRNAs (miR-222 and miR-483-5p) in the serum were proven to differentiate CCA patients from PSC patients in a retrospective study including a discovery $(n=90)$ and a validation cohort $(n=140),{ }^{73}$ showing the promise of circulating miR-
NAs. Additional experiences showed a good negative predictive value for circulating miRNA signatures that were able to correctly identify 12 out of 13 patients with PSC who did not develop CCA. ${ }^{74}$ However, circulating miRNAs in the blood are known to be affected by other conditions, such as liver injury, cardiovascular disease, sepsis, and immunological disorders, and therefore the use of circulating miRNAs should be applied with caution in the clinical practice in view of their limited positive predictive value. A way to overcome this issue is to search for CCA-specific miRNAs in the bile. Owing to the direct contact, diagnostic information could be obtained in the bile where tumor-related biomarkers may have increased concentrations and conversely non-tumor markers may be less represented. ${ }^{71}$ Moreover, an increasing number of studies have shown that the EVs released into the bile of individuals affected by liver disease differ in functional content to those found in the bile of healthy individuals. Li et al provided the first evidence that human bile contains miRNA-laden EVs, ${ }^{75}$ thus paving the way for the exploitation of their biomarker potential in biliary tract diseases. Using a multivariate 
combinatorial model, researchers were able to define a novel bile-based 5-miRNA panel (miR-191, miR-486-3p, miR1274b, miR-16, and miR484) for CCA diagnosis that had $67 \%$ sensitivity and $96 \%$ specificity. Notably, this diagnostic tool was more accurate than the commonly available standard methods used in clinical practice (e.g., CA19-9). More interestingly, of the 11 CCA patients correctly diagnosed by the 5miRNA panel, but misdiagnosed by CA19-9, 8 had early-stage disease (NOMO), underlining the potential of this miRNA signature approach to detect cancers in its early stages. It is worth remembering that CCA is endemic in some areas of northeastern Thailand, where the implementation of a screening program could significantly impact on CCA-induced mortality. However, liver fluke-induced CCA has a different genetic and transcriptomic background to the CCA that arises in the Western world. ${ }^{15}$ Thus, it is likely that a miRNA-based diagnostic biomarker for CCA should be specifically targeted to this population limiting the potential of extending studies on Western populations to Eastern populations. The use of urine-based biomarkers is likely to be implemented more successfully in screening programs than those based on the profile of miRNAs in other bodily fluids. MicroRNAs can be detected in the urine given they are filtered through the renal system due to their small size and their high stability. Silakit and coworkers have reported that miR-192 is significantly higher in the urines of 0 . viverrini-infected subjects in comparison to healthy subjects with a sensitivity of $75.0 \%$ and a specificity of $71.4 \%{ }^{76}$ Although good, these values are not high enough to be applied to screening programs, and therefore more work is needed. The measurement of more than one miRNA is likely to represent the best approach for increasing the accuracy of the test. For example, the addition of urinary miR-21 to miR-192 resulted in a test sensitivity of $79.2 \%$ and a specificity of $76.2 \%$, when attempting to distinguish 0 . viverrini-infected subjects from healthy ones. However, it is worth mentioning that miR-21 is increased in a variety of tumors and nonmalignant diseases and lacks specificity as a diagnostic marker.

Cholangiocarcinoma is a disease with unique diagnostic challenges. The detection of dysregulated miRNAs into accessible biofluids in patients harboring a high index of suspicion for CCA offers an opportunity for earlier diagnosis and thus higher chances of curability. However, several issues remain to be addressed. Specimen collection and manipulation must be standardized to derive a test that can be applied in a prospective fashion. We believe that the levels of circulating miRNAs should not be normalized to those of reference transcripts (or miRNAs), as a direct count of the miRNA molecules in a given volume of biofluid is likely to represent the most accurate method for clinical implementation. The advancement in technologies with the introduction of digital PCR and RNA sequencing should render it possible to directly count such molecules and identify a threshold that can be applied for prospective validation. However, it is certain that large patient cohorts are needed to investigate the distribution of circulating miRNAs in the population at risk, and to understand their association with CCA development in a manner that is independent of other comorbidities. In tumors with a low prevalence, such as CCA, this goal can only be achieved through a collaborative international effort. We can speculate that the detection of miRNAs within CCAspecific EVs can improve diagnostic accuracy, and that the ongoing efforts to extensively characterize EVs will identify markers enriched in CCA-specific EVs to achieve this goal $^{77,78}$ (and their ncRNA content). A more provocative question could be: "Do we need to identify a miRNA that is cancer-specific to improve early diagnosis and promote prevention?" We have learnt from the latest advances in oncology that the host immune response plays a driving role in containing and attacking cancer, enabling the "defeat" of cancer even in cases of multi-metastatic disease. ${ }^{79-81}$ It is reasonable to speculate that the immune system is playing even a more important role in the early stages of malignant transformation and that detecting markers that are indicative of the failure of the host immune response may be informative for early diagnosis. Given the evidence that ncRNAs can drive the fate of immune cells and their function, ${ }^{69}$ it may be useful to start looking for changes in ncRNAs that reflect a poor immunological response rather than the presence of a cancer that has already developed.

\section{Prognostic Role}

Based on the identification of ncRNAs as drivers of CCA progression, growing research efforts are attempting to identify CCA-related miRNA signatures that could inform disease prognosis and patient selection. In a cohort of 84 patients with iCCA, high expression of miR-191 was found to be independently associated with worse disease-free survival and OS. ${ }^{28}$ miR-21 has also been consistently found to be associated with adverse clinicopathological features and survival. $^{82}$ More interestingly, circulating miR-21 levels dropped in patients undergoing curative surgery, but not in those receiving palliative resection, suggesting that the levels of miR-21 in the plasma reflect the extent of the tumor and can be used as a surrogate marker for prognosis. Likewise, high serum miR-26a expression has been significantly correlated with clinical stage, distant metastasis, differentiation status, and the poor survival of CCA patients. ${ }^{83}$ Looking for highly expressed miRNAs may be less technically challenging than looking for downregulated miRNAs, where absence or low levels can also be associated with technical failure. However, recent evidence support a prognostic role for low tissue levels of miR-203, a tumor suppressor miRNA, in resected CCA. ${ }^{84}$ With the introduction of adjuvant chemotherapy in the management of resected CCA, the discovery of a prognostic marker may represent a valuable asset for identifying those patients who are most likely to benefit from postoperative treatment. In this regard, it is likely that the study of tissue and circulating (where possible) miRNAs, in large cohorts in prospective clinical trials, will offer more insight than the investigation of the clinical value of ncRNAs in small retrospective series. The availability of tissue from resected tumors in this setting offers an additional opportunity for ncRNA detection by using in situ technologies that enable a semiquantitative score that can be easily 
implemented in the clinic. We and others have previously shown that cancer can be classified on the basis of ncRNA expression measured using in situ hybridization techniques in formalin-fixed paraffin-embedded tissue and scored following the methods used for immunohistochemistry. ${ }^{67,85}$

\section{Predictive Role}

Chemotherapy still represents the mainstay of advanced CCA treatment, while targeted agents and immunotherapy have shown potential in selected patient populations. ${ }^{9,86,87}$ Active chemotherapy regimens include gemcitabine, capecitabine, and a combination of cisplatin and gemcitabine (CG) or of fluorouracil and oxaliplatin (FOLFOX) ${ }^{11,88,89}$. With an increasing number of treatment options on the horizon, the need for personalized medicine is emerging. However, the window of opportunity for treatment in CCA patients is limited, because of the rapid deterioration in patients' fitness upon chemotherapy failure. Indeed, while some patients that fail to respond to first-line chemotherapy may still be sensitive to second-line options, a rapid drop in their performance status might preclude further lines of therapy. A better understanding of the mechanisms underpinning chemoresistance will improve patient selection and provide important tools to enable decision-making in regard to the choice of chemotherapy sequence, achieving rapid disease control in responders and minimizing the risk of unnecessary toxicity in patients who are unlikely to benefit.

Aberrantly expressed miRNAs in cancer cells are thought to regulate the expression of genes critical for cell survival in response to chemotherapeutic stress. For instance, miR-21 expression was shown to increase following exposure to cytotoxic drugs and to modulate gemcitabine-induced apoptosis by phosphatase and tensin homolog (PTEN)-dependent activation of PI3-kinase signaling in in vitro and in vivo models. ${ }^{24}$ In other reports, the loss of selected miRNAs (miR29, miR-320, and miR-204) was found to mediate the resistance of CCA cells to chemotherapeutics, by acting on the apoptotic pathway. ${ }^{90,91}$ Although preclinical, these observations link ncRNAs with the sensitivity of tumor cells to chemotherapy and suggest that ncRNAs should be investigated in the translational component of large clinical trials. The possibility of detecting circulating miRNAs in the blood of CCA patients increases the applicability of such tests in the advanced disease setting where tissue availability is limited. In addition, as described earlier, circulating miRNAs can be affected by other comorbidities and thus have the potential to represent surrogate markers of the general medical status of the patient, information on which treatment choice can be based.

miRNAs can drive several cellular processes and, therefore, have the potential to modulate cell sensitivity to several nonchemotherapy drugs. We, and others, have recently proven that heat shock protein 90 (HSP90) inhibition can be a promising therapeutic strategy in CCA. ${ }^{92,93}$ The HSP90 complex interacts with a variety of client proteins, which have a key role in CCA progression, such as epidermal growth factor receptor (EGFR), phosphoinositide-3-kinase, PTEN, human epidermal growth factor receptor 2, human epidermal growth factor receptor 3 , and phosphoribulokinase A. Moreover, inhibition of HSP90 seems to be remarkably effective in tumors with fibroblast growth factor receptor fusions and activation of the IL-6/STAT pathway. ${ }^{94,95}$ HSP90 controls the post-translational folding of argonaute2 (AGO2), a regulator of miRNA processing, ${ }^{96}$ suggesting that miRNAs could represent good biomarker candidates. We have shown that miR-21 can drive resistance to HSP90 inhibition by specifically affecting the multi-chaperone complex in a way that is recapitulated in human CCA cell lines, 3D organoid structures, and patient-derived xenografts. ${ }^{92}$ Given the potential of miRNAs to affect a range of signaling pathways, we suggest to include ncRNAs within future drug discovery projects expanding our pivotal experience. Patientderived organoids (PDOs) are organotypic cultures that recapitulate the architecture, genomic- and transcriptomic-profile of human tumors, and mimic their treatment response in the clinic, holding great potential in advancing drug discovery projects. We recently provided evidence that PDOs can be established from tissue derived from advanced CCA patients and can be manipulated to change miRNA expression, opening the way for the use of PDOs as a tool to personalize medicine and apply functional genomics to identify the involvement of ncRNAs in the response to drugs in CCA. ${ }^{92}$

\section{ncRNA-Based Therapeutics}

Insights into the role of ncRNAs in tumor biology, alongside their ability to target multiple genes and signaling pathways simultaneously, have made them attractive targets and therapeutic tools for novel anticancer approaches. The two main strategies for modulating miRNA expression are based on the introduction of synthetically derived small RNA duplexes that behave similarly to endogenous miRNAs (miRNA mimics) or, conversely, on the delivery of molecules targeted at miRNAs (anti-miRNAs or miRNAs inhibitors). In the former case, the aim is to replenish the lost expression of miRNAs acting as tumor suppressor, whereas in the latter case the aim is to oppose the function of oncogenic miRNAs. ${ }^{97}$ In both cases, appropriate target selection as well as strategies for tissue/cancer-specific in vivo delivery are critical steps to pursue the therapeutic goal while minimizing off-target effects and toxicities. The identification of the best miRNA targets is challenging, mainly because no miRNAs are entirely cancer-specific and conditions such as inflammation and hypoxia can affect miRNA expression, complicating the search for candidate miRNAs. ${ }^{98}$ Moreover, the concept of temporal and spatial heterogeneity applies also to miRNAs, whose expression is dynamic over time and may vary intertumorally and intratumorally. Among the strategies being used to select key regulatory miRNAs is miRNA crosslinking and immunoprecipitation (miR-CLIP), a novel technique that can identify relevant miRNA pathways by capturing their putative targets, the so-called "targetome" 99 . The matching of these data or other from public repositories on miRNA interaction networks with prediction platforms will allow for a more accurate identification of best candidate miRNAs to be targeted. An additional strategy to look for key regulatory miRNAs is based on genome-wide high-throughput screening technologies to evaluate libraries of miRNA mimics or inhibitors. 
The degradation of naked particles by nucleases is a key issue, which needs to be overcome before implementing miRNA-based therapeutics. To optimize the delivery of miRNA mimics/anti-miRNAs, their nucleotide backbone can be chemically modified to improve their stability in bodily fluids and prevent degradation in serum and endocytic cellular compartments. However, oligonucleotide methylation, the introduction of locked nucleic acids, or the addition of phosphorothioate-like groups can result not only in an increase in miRNA stability but also in the loss of mRNA silencing, or in off-target effects and the production of toxic metabolites. The ideal delivery vehicle would be a nonimmunogenic and biodegradable carrier, displaying target tumor specificity and robust binding. One of the most successful approaches is to encapsulate the miRNA mimics/antimiRNAs into nanoparticles. Poly(lactide-co-glycolide) particles, neutral lipid emulsions, neutral liposome 1,2-dioleoylsn-glycero-3-phosphatidylcholine, polyethylenimine, polyethylene glycol, chitosan and n-acetyl-d-galactosamine are all promising platforms for miRNA therapeutics delivery that are currently being tested in clinical trials. However, both the efficiency with which miRNA mimics/anti-miRNAs are delivered to the target site and their safety profile are still suboptimal, partly as a result of the net cationic charge of the carriers.

The strategy of replenishing miRNAs with tumor-suppressive function in vivo has recently been pursued in humans. Van Zandwijk et al reported the results of the first-in-man phase 1 trial with a miR-16 mimic, which was administered to patients with recurrent malignant pleural mesothelioma. ${ }^{100}$ Minicells loaded with a miR-16-based miRNA mimic and targeted to EGFR (TargomiRs) were administered to 26 patients with EGFR immunohistochemical expression that had disease progression after receiving standard chemotherapy. TargomiRs were given over a 20-minute intravenous infusion either once or twice weekly according to a traditional $3+3$ dose-escalation design across 5 dose cohorts. Among 22 assessable patients, one $(5 \%)$ had a partial response and 15 (68\%) had stable disease. These encouraging data show how the delivery of miRNA mimics can be a clinically feasible and effective approach. However, toxicity concerns remain, as in this study the TargomiR-induced cardiotoxicity in 5 patients. The exact mechanism responsible for the cardiological toxicity is still not clear, as it may be a direct effect of the miRNA itself or the consequence of the inflammatory reaction induced by the minicell delivery vehicle. Advances in technology are likely to yield safer delivery methods, which can increase efficacy and reduce the toxicity associated with this therapeutic strategy. Moreover, pharmacological studies and the assessment of miRNA in the tumor tissue after administration of the miRNA-based therapeutics should be included in future studies to better understand the dynamics of the systemic delivery of these new therapeutics. On a different standpoint, targeting of miR-122 proved successful in a phase $2 \mathrm{a}$ trial in patients with chronic HCV genotype 1 infection. ${ }^{101}$ A 15 -nucleotide locked nucleic acid-modified DNA phosphorothioate antisense oligonucleotide (Miravirsen) was given in a random fashion to 36 patients, who had been subdivided into four groups and given doses of 3 ,
5 , or $7 \mathrm{mg} / \mathrm{kg}$, or a placebo, over a 29-day period. Prolonged dose-dependent reductions in HCV RNA levels were observed, with no dose-limiting toxicities, no evidence of viral resistance or occurrence of hepatocellular carcinoma. With regard to liver tumors, MRX34, a liposomal miR-34 mimic, has been the first miRNA mimic to enter clinical evaluation in patients with solid tumors, including hepatocellular carcinoma. ${ }^{102}$ In this phase I, first-in-human, dose-escalation study, MRX34 was administered intravenously biweekly or daily (x 5 days) to 99 patients with advanced solid tumors. MRX34 had a manageable safety profile, as the most commonly reported adverse events were mild in grade (fever, chills, fatigue, back pain, and nausea), with grade 3 lymphocytopenia, thrombocytopenia, elevated AST, neutropenia, and hyponatremia as the more frequent laboratory abnormalities. This liposomal miR-34 mimic displayed anticancer activity, achieving a prolonged confirmed RECIST partial response in 3 patients (one of whom had hepatocellular carcinoma), and stable disease in 14 other cases. A phase Ia expansion cohorts is currently underway and phase II studies are being planned (Clinical trial information: NCT01829971). Recent preclinical evidence showed that this miR34 mimic can also suppress the growth of CCA cells, ${ }^{103}$ suggesting that this investigation could be extended to CCA patients.

\section{Conclusion}

Cholangiocarcinoma is characterized by late diagnosis and poor response to standard treatment resulting in an almost invariably dismal prognosis. Therefore, there is an urgent need for earlier diagnosis, a better prediction for tumor aggressiveness and response to treatment as well as novel therapeutic options. The better understanding of CCA biology has revealed ncRNAs as pivotal players affecting CCA initiation, progression, and treatment resistance. On these premises, ncRNAs are being studied intensively as promising tumor biomarkers to incorporate in the clinical management for improving the outcome of CCA patients. ${ }^{104}$ Preliminary findings are encouraging, even though further research is required to confirm their reliability and clinical reproducibility.

\section{Main Concepts and Learning Points}

- Cholangiocarcinoma is a rare and heterogeneous tumor entity with a poor prognosis and limited therapeutic options.

- Noncoding RNAs are classified according to their length into small (18 to 200 nucleotides) and long ( $>200$ nucleotides) RNAs, and according to their function into housekeeping (e. g., ribosomal RNA and transfer RNA) and regulatory (e.g., microRNA, piwi-interacting RNA, long ncRNA) RNAs.

- Dysregulation of ncRNAs has been implicated in cholangiocarcinogenesis, tumor progression, and chemotherapy resistance.

- microRNAs have been isolated and characterized in both the primary tumor tissue and bodily fluids (serum, plasma, urine, and bile) of patients with CCA.

- microRNAs hold the potential to be introduced into the clinic as diagnostic, prognostic, and predictive biomarkers 
for CCA. Efforts to design therapeutics that deregulate ncRNAs are ongoing.

\section{Conflicts of Interest}

The authors have no conflict of interest to declare.

\section{Acknowledgments}

Chiara Braconi is the recipient of an Institute of Cancer Research Clinician Scientist Fellowship, an Early Diagnosis Award from Pancreatic Cancer Action and an NIHR Royal Marsden/ICR Biomedical Research Centre project grant. This work was supported in part by LILT Modena Onlus. The authors thank Nicky Evans for her editorial assistance.

\section{References}

1 Braconi C, Patel T. Cholangiocarcinoma: new insights into disease pathogenesis and biology. Infect Dis Clin North Am 2010;24 (04):871-884, vii

2 Marcano-Bonilla L, Mohamed EA, Mounajjed T, Roberts LR. Biliary tract cancers: epidemiology, molecular pathogenesis and genetic risk associations. Linchuang Zhongliuxue Zazhi 2016;5(05):61

3 Saha SK, Zhu AX, Fuchs CS, Brooks GA. Forty-year trends in cholangiocarcinoma incidence in the U.S.: intrahepatic disease on the rise. Oncologist 2016;21(05):594-599

4 Fitzmaurice C, Akinyemiju TF, Al Lami FH, et al. Global, Regional, and National Cancer Incidence, Mortality, Years of Life Lost, Years Lived With Disability, and Disability-Adjusted Life-Years for 29 Cancer Groups, 1990 to 2016: A Systematic Analysis for the Global Burden of Disease Study. JAMA Oncol 2018;4(11): 1553-1568

5 Rizvi S, Khan SA, Hallemeier CL, Kelley RK, Gores GJ. Cholangiocarcinoma: evolving concepts and therapeutic strategies. Nat Rev Clin Oncol 2018;15(02):95-111

6 Patel T. Increasing incidence and mortality of primary intrahepatic cholangiocarcinoma in the United States. Hepatology 2001; 33(06):1353-1357

7 Bridgewater J, Galle PR, Khan SA, et al. Guidelines for the diagnosis and management of intrahepatic cholangiocarcinoma. J Hepatol 2014;60(06):1268-1289

8 Rizvi S, Gores GJ. Pathogenesis, diagnosis, and management of cholangiocarcinoma. Gastroenterology 2013;145(06):1215-1229

9 Valle JW, Borbath I, Khan SA, Huguet F, Gruenberger T, Arnold D; ESMO Guidelines Committee. Biliary cancer: ESMO Clinical Practice Guidelines for diagnosis, treatment and follow-up. Ann Oncol 2016;27(Suppl 5):v28-v37

10 Razumilava N, Gores GJ. Cholangiocarcinoma. Lancet 2014;383 (9935):2168-2179

11 Valle J, Wasan H, Palmer DH, et al; ABC-02 Trial Investigators. Cisplatin plus gemcitabine versus gemcitabine for biliary tract cancer. N Engl J Med 2010;362(14):1273-1281

12 Valle JW, Furuse J, Jitlal M, et al. Cisplatin and gemcitabine for advanced biliary tract cancer: a meta-analysis of two randomised trials. Ann Oncol 2014;25(02):391-398

13 Croce CM. Causes and consequences of microRNA dysregulation in cancer. Nat Rev Genet 2009;10(10):704-714

14 Valle JW, Lamarca A, Goyal L, Barriuso J, Zhu AX. New horizons for precision medicine in biliary tract cancers. Cancer Discov 2017;7(09):943-962

15 Chan-On W, Nairismägi ML, Ong CK, et al. Exome sequencing identifies distinct mutational patterns in liver fluke-related and non-infection-related bile duct cancers. Nat Genet 2013;45(12): 1474-1478

16 Jusakul A, Cutcutache I, Yong $\mathrm{CH}$, et al. Whole-genome and epigenomic landscapes of etiologically distinct subtypes of cholangiocarcinoma. Cancer Discov 2017;7(10):1116-1135
17 Farshidfar F, Zheng S, Gingras MC, et al; Cancer Genome Atlas Network. Integrative genomic analysis of cholangiocarcinoma identifies distinct IDH-mutant molecular profiles. Cell Reports 2017;19(13):2878-2880

18 Pennisi E. Genomics. ENCODE project writes eulogy for junk DNA. Science 2012;337(6099)1159-1161

19 Dozmorov MG, Giles CB, Koelsch KA, Wren JD. Systematic classification of non-coding RNAs by epigenomic similarity. BMC Bioinformatics 2013;14(Suppl 14):S2

20 Lewis BP, Burge CB, Bartel DP. Conserved seed pairing, often flanked by adenosines, indicates that thousands of human genes are microRNA targets. Cell 2005;120(01):15-20

21 Ling H, Fabbri M, Calin GA. MicroRNAs and other non-coding RNAs as targets for anticancer drug development. Nat Rev Drug Discov 2013;12(11):847-865

22 Lu J, Getz G, Miska EA, et al. MicroRNA expression profiles classify human cancers. Nature 2005;435(7043)834-838

23 Volinia S, Calin GA, Liu CG, et al. A microRNA expression signature of human solid tumors defines cancer gene targets. Proc Natl Acad Sci U S A 2006;103(07):2257-2261

24 Meng F, Henson R, Lang M, et al. Involvement of human microRNA in growth and response to chemotherapy in human cholangiocarcinoma cell lines. Gastroenterology 2006;130(07): 2113-2129

25 Selaru FM, Olaru AV, Kan T, et al. MicroRNA-21 is overexpressed in human cholangiocarcinoma and regulates programmed cell death 4 and tissue inhibitor of metalloproteinase 3. Hepatology 2009;49(05):1595-1601

26 Zhang J, Han C, Wu T. MicroRNA-26a promotes cholangiocarcinoma growth by activating $\beta$-catenin. Gastroenterology 2012; 143(01):246-56.e8

27 Wang XW, Heegaard NH, Orum H. MicroRNAs in liver disease. Gastroenterology 2012;142(07):1431-1443

$28 \mathrm{Li} \mathrm{H}$, Zhou ZQ Yang ZR, et al. MicroRNA-191 acts as a tumor promoter by modulating the TET1-p53 pathway in intrahepatic cholangiocarcinoma. Hepatology 2017;66(01):136-151

29 Wang J, Xie H, Ling Q et al. Coding-noncoding gene expression in intrahepatic cholangiocarcinoma. Transl Res 2016;168:107-121

30 Olaru AV, Ghiaur G, Yamanaka S, et al. MicroRNA down-regulated in human cholangiocarcinoma control cell cycle through multiple targets involved in the G1/S checkpoint. Hepatology 2011;54(06):2089-2098

31 Mott JL, Kobayashi S, Bronk SF, Gores GJ. mir-29 regulates Mcl-1 protein expression and apoptosis. Oncogene 2007;26(42): 6133-6140

32 Razumilava N, Bronk SF, Smoot RL, et al. miR-25 targets TNFrelated apoptosis inducing ligand (TRAIL) death receptor-4 and promotes apoptosis resistance in cholangiocarcinoma. Hepatology 2012;55(02):465-475

33 Oishi N, Kumar MR, Roessler S, et al. Transcriptomic profiling reveals hepatic stem-like gene signatures and interplay of miR200c and epithelial-mesenchymal transition in intrahepatic cholangiocarcinoma. Hepatology 2012;56(05):1792-1803

34 Liu Z, Jin ZY, Liu CH, Xie F, Lin XS, Huang Q. MicroRNA-21 regulates biological behavior by inducing EMT in human cholangiocarcinoma. Int J Clin Exp Pathol 2015;8(05):4684-4694

35 Liu CH, Huang Q, Jin ZY, Zhu CL, Liu Z, Wang C. miR-21 and KLF4 jointly augment epithelial-mesenchymal transition via the Akt/ ERK1/2 pathway. Int J Oncol 2017;50(04):1109-1115

36 Li B, Han Q Zhu Y, Yu Y, Wang J, Jiang X. Down-regulation of miR214 contributes to intrahepatic cholangiocarcinoma metastasis by targeting twist. FEBS J 2012;279(13):2393-2398

37 Li J, Yao L, Li G, et al. miR-221 promotes epithelial-mesenchymal transition through targeting PTEN and forms a positive feedback loop with $\beta$-catenin/c-Jun signaling pathway in extra-hepatic cholangiocarcinoma. PLoS ONE 2015;10(10):e0141168

38 Wang Q Tang H, Yin S, Dong C. Downregulation of microRNA138 enhances the proliferation, migration and invasion of 
cholangiocarcinoma cells through the upregulation of RhoC/pERK/MMP-2/MMP-9. Oncol Rep 2013;29(05):2046-2052

39 Park J, Tadlock L, Gores GJ, Patel T. Inhibition of interleukin 6mediated mitogen-activated protein kinase activation attenuates growth of a cholangiocarcinoma cell line. Hepatology 1999; 30(05):1128-1133

40 Meng F, Yamagiwa Y, Ueno Y, Patel T. Over-expression of interleukin6 enhances cell survival and transformed cell growth in human malignant cholangiocytes. J Hepatol 2006;44(06):1055-1065

41 Lin KY, Ye H, Han BW, et al. Genome-wide screen identified let7c/miR-99a/miR-125b regulating tumor progression and stemlike properties in cholangiocarcinoma. Oncogene 2016;35(26): 3376-3386

42 Meng F, Henson R, Wehbe-Janek H, Smith H, Ueno Y, Patel T. The MicroRNA let-7a modulates interleukin-6-dependent STAT-3 survival signaling in malignant human cholangiocytes. J Biol Chem 2007;282(11):8256-8264

43 Meng F, Wehbe-Janek H, Henson R, Smith H, Patel T. Epigenetic regulation of microRNA-370 by interleukin-6 in malignant human cholangiocytes. Oncogene 2008;27(03):378-386

44 Braconi C, Huang N, Patel T. MicroRNA-dependent regulation of DNA methyltransferase-1 and tumor suppressor gene expression by interleukin- 6 in human malignant cholangiocytes. Hepatology 2010;51(03):881-890 Doi: 10.1002/hep.23381

45 Plieskatt JL, Rinaldi G, Feng Y, et al. Distinct miRNA signatures associate with subtypes of cholangiocarcinoma from infection with the tumourigenic liver fluke Opisthorchis viverrini. J Hepatol 2014;61(04):850-858

46 Chusorn P, Namwat N, Loilome W, et al. Overexpression of microRNA-21 regulating PDCD4 during tumorigenesis of liver fluke-associated cholangiocarcinoma contributes to tumor growth and metastasis. Tumour Biol 2013;34(03):1579-1588

47 Raggi C, Invernizzi P, Andersen JB. Impact of microenvironment and stem-like plasticity in cholangiocarcinoma: molecular networks and biological concepts. J Hepatol 2015;62(01):198-207

48 Mertens JC, Fingas CD, Christensen JD, et al. Therapeutic effects of deleting cancer-associated fibroblasts in cholangiocarcinoma. Cancer Res 2013;73(02):897-907

49 Utaijaratrasmi P, Vaeteewoottacharn K, Tsunematsu T, et al. The microRNA-15a-PAI-2 axis in cholangiocarcinoma-associated fibroblasts promotes migration of cancer cells. Mol Cancer 2018;17(01):10

50 Kogure T, Yan IK, Lin WL, Patel T. Extracellular vesicle-mediated transfer of a novel long noncoding RNA TUC339: a mechanism of intercellular signaling in human hepatocellular cancer. Genes Cancer 2013;4(7-8):261-272

51 Kogure T, Lin WL, Yan IK, Braconi C, Patel T. Intercellular nanovesicle-mediated microRNA transfer: a mechanism of environmental modulation of hepatocellular cancer cell growth. Hepatology 2011;54(04):1237-1248

52 Masyuk AI, Huang BQ Ward CJ, et al. Biliary exosomes influence cholangiocyte regulatory mechanisms and proliferation through interaction with primary cilia. Am J Physiol Gastrointest Liver Physiol 2010;299(04):G990-G999

53 Sirica AE. The role of cancer-associated myofibroblasts in intrahepatic cholangiocarcinoma. Nat Rev Gastroenterol Hepatol 2011;9(01):44-54

54 Haga H, Yan IK, Takahashi K, Wood J, Zubair A, Patel T. Tumour cell-derived extracellular vesicles interact with mesenchymal stem cells to modulate the microenvironment and enhance cholangiocarcinoma growth. J Extracell Vesicles 2015;4:24900

55 Li L, Piontek K, Ishida M, et al. Extracellular vesicles carry microRNA-195 to intrahepatic cholangiocarcinoma and improve survival in a rat model. Hepatology 2017;65(02):501-514

56 Schmitt AM, Chang HY. Long noncoding RNAs in cancer pathways. Cancer Cell 2016;29(04):452-463

57 Xu Y, Wang Z, Jiang X, Cui Y. Overexpression of long noncoding RNA H19 indicates a poor prognosis for cholangiocarcinoma and promotes cell migration and invasion by affecting epithelialmesenchymal transition. Biomed Pharmacother 2017;92:17-23

58 Lu X, Zhou C, Li R, Deng Y, Zhao L, Zhai W. Long noncoding RNA AFAP1-AS1 promoted tumor growth and invasion in cholangiocarcinoma. Cell Physiol Biochem 2017;42(01):222-230

59 Ma SL, Li AJ, Hu ZY, Shang FS, Wu MC. Co-expression of the carbamoyl-phosphate synthase 1 gene and its long non-coding RNA correlates with poor prognosis of patients with intrahepatic cholangiocarcinoma. Mol Med Rep 2015;12(06):7915-7926

60 Wang C, Mao ZP, Wang L, et al. Long non-coding RNA MALAT1 promotes cholangiocarcinoma cell proliferation and invasion by activating PI3K/Akt pathway. Neoplasma 2017;64(05):725-731

$61 \mathrm{Xu}$ Y, Jiang X, Cui Y. Upregulated long noncoding RNA PANDAR predicts an unfavorable prognosis and promotes tumorigenesis in cholangiocarcinoma. Onco Targets Ther 2017;10:2873-2883

62 Jiang XM, Li ZL, Li JL, et al. LncRNA CCAT1 as the unfavorable prognostic biomarker for cholangiocarcinoma. Eur Rev Med Pharmacol Sci 2017;21(06):1242-1247

$63 \mathrm{Xu}$ Y, Leng K, Li Z, et al. The prognostic potential and carcinogenesis of long non-coding RNA TUG1 in human cholangiocarcinoma. Oncotarget 2017;8(39):65823-65835

64 Zhang F, Wan M, Xu Y, et al. Long noncoding RNA PCAT1 regulates extrahepatic cholangiocarcinoma progression via the $\mathrm{Wnt} / \mathrm{B}$-catenin-signaling pathway. Biomed Pharmacother 2017;94:55-62

65 Wang WT, Ye H, Wei PP, et al. LncRNAs H19 and HULC, activated by oxidative stress, promote cell migration and invasion in cholangiocarcinoma through a ceRNA manner. J Hematol Oncol 2016;9(01):117

66 Carotenuto P, Fassan M, Pandolfo R, et al. Wht signalling modulates transcribed-ultraconserved regions in hepatobiliary cancers. Gut 2017;66(07):1268-1277

67 Iyer MK, Niknafs YS, Malik R, et al. The landscape of long noncoding RNAs in the human transcriptome. Nat Genet 2015; 47(03):199-208

68 Braconi C, Valeri N, Kogure T, et al. Expression and functional role of a transcribed noncoding RNA with an ultraconserved element in hepatocellular carcinoma. Proc Natl Acad Sci U S A 2011;108 (02):786-791

69 Ranzani V, Rossetti G, Panzeri I, et al. The long intergenic noncoding RNA landscape of human lymphocytes highlights the regulation of $\mathrm{T}$ cell differentiation by linc-MAF-4. Nat Immunol 2015;16(03):318-325

70 Arroyo JD, Chevillet JR, Kroh EM, et al. Argonaute2 complexes carry a population of circulating microRNAs independent of vesicles in human plasma. Proc Natl Acad Sci U S A 2011;108 (12):5003-5008

71 Cortez MA, Bueso-Ramos C, Ferdin J, Lopez-Berestein G, Sood AK, Calin GA. MicroRNAs in body fluids: the mix of hormones and biomarkers. Nat Rev Clin Oncol 2011;8(08):467-477

72 Patel T. Extracellular vesicle noncoding RNA: new players in the diagnosis and pathogenesis of cholangiocarcinoma. Hepatology 2014;60(03):782-784

73 Bernuzzi F, Marabita F, Lleo A, et al. Serum microRNAs as novel biomarkers for primary sclerosing cholangitis and cholangiocarcinoma. Clin Exp Immunol 2016;185(01):61-71

74 Voigtländer T, Gupta SK, Thum S, et al. MicroRNAs in serum and bile of patients with primary sclerosing cholangitis and/or cholangiocarcinoma. PLoS One 2015;10(10):e0139305

75 Li L, Masica D, Ishida M, et al. Human bile contains microRNAladen extracellular vesicles that can be used for cholangiocarcinoma diagnosis. Hepatology 2014;60(03):896-907

76 Silakit R, Loilome W, Yongvanit P, et al. Urinary microRNA-192 and microRNA-21 as potential indicators for liver fluke-associated cholangiocarcinoma risk group. Parasitol Int 2017;66(04):479-485

77 Arbelaiz A, Azkargorta M, Krawczyk M, et al. Serum extracellular vesicles contain protein biomarkers for primary sclerosing cholangitis and cholangiocarcinoma. Hepatology 2017;66(04): 1125-1143 
78 Julich-Haertel H, Urban SK, Krawczyk M, et al. Cancer-associated circulating large extracellular vesicles in cholangiocarcinoma and hepatocellular carcinoma. J Hepatol 2017;67(02): 282-292

79 Hodi FS, O'Day SJ, McDermott DF, et al. Improved survival with ipilimumab in patients with metastatic melanoma. $\mathrm{N}$ Engl J Med 2010;363(08):711-723

80 Robert C, Long GV, Brady B, et al. Nivolumab in previously untreated melanoma without BRAF mutation. N Engl J Med 2015;372(04):320-330

81 Robert C, Schachter J, Long GV, et al; KEYNOTE-006 investigators. Pembrolizumab versus ipilimumab in advanced melanoma. N Engl J Med 2015;372(26):2521-2532

82 Wang LJ, He CC, Sui X, et al. MiR-21 promotes intrahepatic cholangiocarcinoma proliferation and growth in vitro and in vivo by targeting PTPN14 and PTEN. Oncotarget 2015;6(08): 5932-5946

83 Wang LJ, Zhang KL, Zhang N, et al. Serum miR-26a as a diagnostic and prognostic biomarker in cholangiocarcinoma. Oncotarget 2015;6(21):18631-18640

84 Li J, Gao B, Huang Z, et al. Prognostic significance of microRNA203 in cholangiocarcinoma. Int J Clin Exp Pathol 2015;8(08): 9512-9516

85 Valeri N, Gasparini P, Fabbri M, et al. Modulation of mismatch repair and genomic stability by miR-155. Proc Natl Acad Sci U S A 2010;107(15):6982-6987

86 Goyal L, Saha SK, Liu LY, et al. Polyclonal secondary FGFR2 mutations drive acquired resistance to FGFR inhibition in patients with FGFR2 fusion-positive cholangiocarcinoma. Cancer Discov 2017;7(03):252-263

87 Javle M, Lowery M, Shroff RT, et al. Phase II Study of BGJ398 in Patients With FGFR-Altered Advanced Cholangiocarcinoma. J Clin Oncol 2018;36(03):276-282

88 Novarino AMT, Satolli MA, Chiappino I, et al. FOLFOX-4 regimen or single-agent gemcitabine as first-line chemotherapy in advanced biliary tract cancer. Am J Clin Oncol 2013;36(05): 466-471

89 He S, Shen J, Sun X, Liu L, Dong J. A phase II FOLFOX-4 regimen as second-line treatment in advanced biliary tract cancer refractory to gemcitabine/cisplatin. J Chemother 2014;26(04):243-247

90 Okamoto K, Miyoshi K, Murawaki Y. miR-29b, miR-205 and miR221 enhance chemosensitivity to gemcitabine in HuH28 human cholangiocarcinoma cells. PLoS ONE 2013;8(10):e77623

91 Chen L, Yan HX, Yang W, et al. The role of microRNA expression pattern in human intrahepatic cholangiocarcinoma. J Hepatol 2009;50(02):358-369

92 Lampis A, Carotenuto P, Vlachogiannis G, et al. MIR21 drives resistance to heat shock protein 90 inhibition in cholangiocarcinoma. Gastroenterology 2018;154(04):1066-1079.e5

93 Shirota T, Ojima H, Hiraoka N, et al. Heat shock protein 90 is a potential therapeutic target in cholangiocarcinoma. Mol Cancer Ther 2015;14(09):1985-1993

94 Lin H, Kolosenko I, Björklund AC, et al. An activated JAK/STAT3 pathway and CD45 expression are associated with sensitivity to Hsp90 inhibitors in multiple myeloma. Exp Cell Res 2013;319 (05):600-611

95 Acquaviva J, He S, Zhang C, et al. FGFR3 translocations in bladder cancer: differential sensitivity to HSP90 inhibition based on drug metabolism. Mol Cancer Res 2014;12(07):1042-1054

96 Johnston M, Geoffroy MC, Sobala A, Hay R, Hutvagner G. HSP90 protein stabilizes unloaded argonaute complexes and microscopic P-bodies in human cells. Mol Biol Cell 2010;21(09):1462-1469

97 Rupaimoole R, Slack FJ. MicroRNA therapeutics: towards a new era for the management of cancer and other diseases. Nat Rev Drug Discov 2017;16(03):203-222

98 Rupaimoole R, Wu SY, Pradeep S, et al. Hypoxia-mediated downregulation of miRNA biogenesis promotes tumour progression. Nat Commun 2014;5:5202
99 Imig J, Brunschweiger A, Brümmer A, et al. miR-CLIP capture of a miRNA targetome uncovers a lincRNA H19-miR-106a interaction. Nat Chem Biol 2015;11(02):107-114

100 van Zandwijk N, Pavlakis N, Kao SC, et al. Safety and activity of microRNA-loaded minicells in patients with recurrent malignant pleural mesothelioma: a first-in-man, phase 1, open-label, dose-escalation study. Lancet Oncol 2017;18(10):1386-1396

101 Janssen HL, Reesink HW, Lawitz EJ, et al. Treatment of HCV infection by targeting microRNA. N Engl J Med 2013;368(18):1685-1694

102 Hong DS, Kang YK, Brenner AJ, et al. MRX34, a liposomal miR34mimic, in patients with advanced solid tumors: final doseescalation results from a first-in-human phase I trial of microRNA therapy. J Clin Oncol 2016;34:2508

103 Han Y, Meng F, Venter J, et al. miR-34a-dependent overexpression of Per1 decreases cholangiocarcinoma growth. J Hepatol 2016;64(06):1295-1304

104 Hahne JC, Valeri N. Non-coding RNAs and resistance to anticancer drugs in gastrointestinal tumors. Front Oncol 2018;8:226

105 Yang H, Li TW, Peng J, et al. A mouse model of cholestasis-associated cholangiocarcinoma and transcription factors involved in progression. Gastroenterology 2011;141(01):378-388, 388.e1-388.e4

106 Zhong XY, Yu JH, Zhang WG, et al. MicroRNA-421 functions as an oncogenic miRNA in biliary tract cancer through down-regulating farnesoid X receptor expression. Gene 2012;493(01):44-51

107 Ehrlich L, Hall C, Venter J, et al. miR-24 inhibition increases menin expression and decreases cholangiocarcinoma proliferation. Am J Pathol 2017;187(03):570-580

108 Qiao P, Li G, Bi W, Yang L, Yao L, Wu D. microRNA-34a inhibits epithelial mesenchymal transition in human cholangiocarcinoma by targeting Smad4 through transforming growth factor-beta/Smad pathway. BMC Cancer 2015;15:469

109 Zhang J, Han C, Zhu H, Song K, Wu T. miR-101 inhibits cholangiocarcinoma angiogenesis through targeting vascular endothelial growth factor (VEGF). Am J Pathol 2013;182(05):1629-1639

110 Zeng B, Li Z, Chen R, et al. Epigenetic regulation of miR-124 by hepatitis $\mathrm{C}$ virus core protein promotes migration and invasion of intrahepatic cholangiocarcinoma cells by targeting SMYD3. FEBS Lett 2012;586(19):3271-3278

111 Yang R, Chen Y, Tang C, et al. MicroRNA-144 suppresses cholangiocarcinoma cell proliferation and invasion through targeting platelet activating factor acetylhydrolase isoform $1 \mathrm{~b}$. BMC Cancer 2014;14:917

112 Peng F, Jiang J, Yu Y, et al. Direct targeting of SUZ12/ROCK2 by $\mathrm{miR}-200 \mathrm{~b} / \mathrm{c}$ inhibits cholangiocarcinoma tumourigenesis and metastasis. Br J Cancer 2013;109(12):3092-3104

113 An F, Yamanaka S, Allen S, et al. Silencing of miR-370 in human cholangiocarcinoma by allelic loss and interleukin- 6 induced maternal to paternal epigenotype switch. PLoS ONE 2012;7(10):e45606

114 Chen Y, Luo J, Tian R, Sun H, Zou S. miR-373 negatively regulates methyl-CpG-binding domain protein 2 (MBD2) in hilar cholangiocarcinoma. Dig Dis Sci 2011;56(06):1693-1701

115 Iwaki J, Kikuchi K, Mizuguchi Y, et al. MiR-376c down-regulation accelerates EGF-dependent migration by targeting GRB2 in the HuCCT1 human intrahepatic cholangiocarcinoma cell line. PLoS One 2013;8(07):e69496

116 Yamanaka S, Campbell NR, An F, et al. Coordinated effects of microRNA-494 induce $\mathrm{G}_{2} / \mathrm{M}$ arrest in human cholangiocarcinoma. Cell Cycle 2012;11(14):2729-2738

117 Cheng Q Feng F, Zhu L, et al. Circulating miR-106a is a novel prognostic and lymph node metastasis indicator for cholangiocarcinoma. Sci Rep 2015;5:16103

118 McNally ME, Collins A, Wojcik SE, et al. Concomitant dysregulation of microRNAs miR-151-3p and miR-126 correlates with improved survival in resected cholangiocarcinoma. HPB 2013;15 (04):260-264

119 Asukai K, Kawamoto K, Eguchi H, et al. Micro-RNA-130a-3p regulates gemcitabine resistance via PPARG in cholangiocarcinoma. Ann Surg Oncol 2017;24(08):2344-2352 